\title{
Comunicação, dessubjetivação e arte
}

\section{NIZIA MARIA VILLAÇA}

\section{Resumo}

Neste texto buscamos refletir sobre os processos de subjetivação/dessubjetivação na arte a partir da noção de dispositivo em Foucault como relação que se estabelece entre os indivíduos e o elemento histórico (Instituições, processos de subjetivação e regras em que se concretizam as relações de poder). Referimos a um conjunto de praxis, saberes, medidas, instituições, cujo objetivo é gerir, governar, controlar e orientar num sentido que se supõe útil, gestos e pensamentos dos homens. A luz deste conceito examinamos a produção e recepção da arte contemporânea.

Palavras-chave: Comunicação, arte, pós-produção 


\section{Communication, desubjectivation and art}

\section{NIZIA MARIA}

\section{Abstract}

In this paper we try to reflect on the processes of subjectivity/desubjectivation in art using the notion of "device" as in Foucault: relationship established between individuals and the historical elements (institutions, procedures of subjectivity and rules, which result in power relations). The auther refers to a set of praxis, knowledges, actions, institutions whose goal is to manage, govern and

Keywords: Communication, art, post-production guide a useful sense gestures and thoughts of men. The production and reception of contemporary art will be thought in this folowing. 
"Eu me organizando posso desorganizar/ Eu desorganizando posso me organizar”.

Chico Science

\begin{abstract}
A discussão sobre os critérios e padrões de julgamento da arte e da cultura em geral, constituem temática de relevante importância no momento de hiperinformação por que passamos. $\mathrm{O}$ processo de interculturalidade proporcionado pela globalização e pelas novas tecnologias cria frequentemente certa perplexidade não apenas junto ao público visitante das expressões contemporâneas, quanto à crítica especializada.
\end{abstract}

Quem tem medo de arte contemporânea? Esta é a pergunta que motiva depoimentos de críticos, curadores e públicos de arte no vídeo produzido pela Fundação Joaquim Nabuco, sem que, na verdade, a grande maioria delas fique longe de qualquer conceituação mais definida.

Neste texto buscamos refletir sobre os processos de subjetivação/dessubjetivação na arte a partir da noção de dispositivo em Foucault como relação que se estabelece entre os indivíduos e o elemento histórico (Instituições, processos de subjetivação e regras em que se concretizam as relações de poder). Referimos a um conjunto de praxis, saberes, medidas, Instituições, cujo objetivo é gerir, governar, controlar e orientar num sentido que se supõe útil, gestos e pensamentos dos homens. Agamben (2009) propõe uma divisão entre os seres viventes de um lado e, do outro, os dispositivos em que estes são capturados. Não só as prisões, os manicômios, o panóptico, as escolas, a confissão, as fábricas, as medidas jurídicas cujas relações com o poder são evidentes, mas também a caneta, a escritura, a literatura, 
a filosofia, a agricultura, o cigarro, a navegação, os computadores, os telefones celulares e por que não a própria linguagem se incluem entre os novos dispositivos. Entre essas duas grandes classes (indivíduos e dispositivos), aparecem os sujeitos como resultado entre o corpo a corpo entre esses dois pólos. Ao ilimitado crescimento dos dispositivos de nosso tempo, responde uma proliferação de processos de subjetivação. A potência do dispositivo é subtrair a subjetivação do desejo do homem por meio da mobilização crescente de narrativas sobre diferentes áreas progressivamente contempladas com rituais sedutores e normalizantes. Cabe ao indivíduo recuperar o que foi capturado de seu campo. Daí a positivação do termo 'profanação', ou seja, restituir ao uso comum aquilo que o sacrifício tinha separado. A arte é um campo privilegiado para tais operações e seu campo um espaço tradicional de guerra.

O desenvolvimento dos dispositivos hoje dificulta tanto a "profanação" quanto a subjetivação. O que define os dispositivos com os quais temos que lidar na atual fase do capitalismo é que eles agem frequentemente por meio de processos da dessubjetivação. $\mathrm{O}$ espectador que passa suas noites diante da televisão recebe em troca de sua dessubjetivação apenas a máscara frustrante do "zappeur" ou sua inclusão no cálculo de índice de audiência.

Vem-nos à lembrança, a ideia de "depressão" a que faz alusão Catherine Grenier (2004) referindo-se à contemporaneidade. Segundo a autora, obras recentes (pinturas, instalações, esculturas, filmes) mostram o homem deprimido separado do presente e do futuro, assim como da socialidade. Uma forma sem sujeito. Esta postura rompe com a atitude do artista moderno voluntariamente inscrito nas margens, numa posição de observador crítico. O deprimido é enraizado no presente e surge desta forma, a psicologia da insuficiência caracterizada pelo sentimento de impotência diante dos próprios ideais numa sociedade capitalista. Nesta linha se inscrevem os palhaços de Ugo Rondinone ou os vídeos onde uma imobilidade mal sã de manequins traduz uma suspensão do sujeito, uma despersonalização que o leva em direção a objetos e animais.

$\mathrm{Na}$ inauguração da exposição com os finalistas do Turner Prize, na Tate Modern, os irmãos Jake e Dinos Chapman, apresentam instalações um tanto escatológicas sobre o corpo humano, com direito a moscas sobre carne viva e ossos aparentes. 

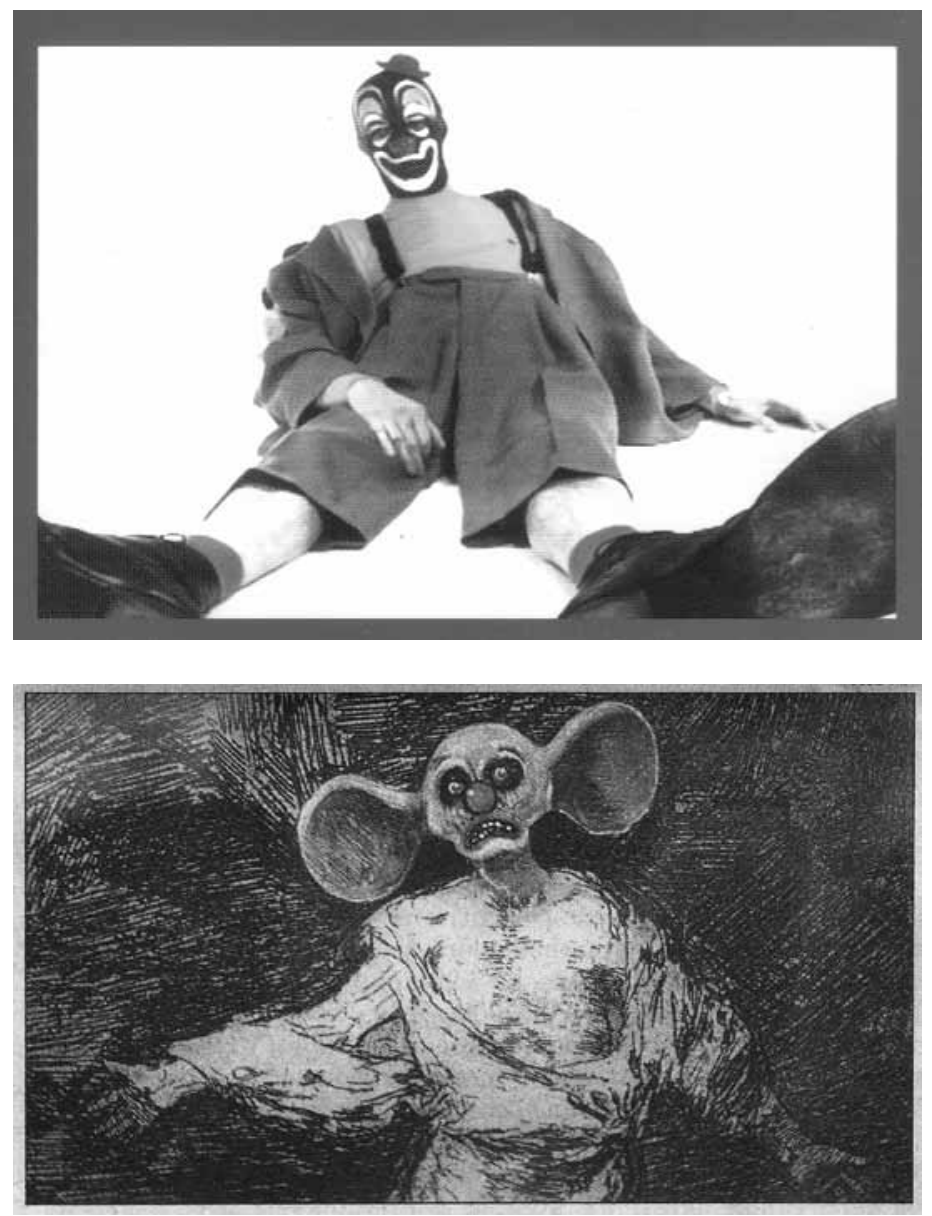

Baudrillard confirma a nova situação e introduz a ideia da telemorfose. O princípio democrático funcionava entre mérito e reconhecimento. No exemplo dado com o efeito Loft, ele remete a uma equivalência total: "a reclusão voluntária como laboratório de uma convivialidade de síntese, duma socialidade telegeneticamente modificada. Quando tudo se dá a ver, nada há a ver. A vida cotidiana transportada em circuito fechado na tela. Estamos com o transporte da vida cotidiana para a tela diante de um equivalente de um ready-made transposição tal e qual da everyday life trucada pelos modelos dominantes". (BAUDRILLARD, 2004, p. 1920). Eleva-se, para o autor, toda a sociedade a uma farsa integral. Sociedade sem contratos, sem regras nem sistema de valor além de cumplicidade reflexa por contagem mediata.
Figura 1: Ugo Rondinone

Figura 2: Jake e Dinos Chapman 
A promiscuidade aponta para uma compulsão ao enclausuramento, seja numa ilha, seja num gueto de luxo onde se vive promiscuamente com a própria imagem. É nesse sentido que Baudrillard vê a Tela Total. Violência da imagem e descrédito da imagem.

No campo da arte, esta parece mimetizar as mídias. Nada escapa do seu obrar: dos detritos que se catam pelo meio das ruas, transformados de lixo em luxo nos museus, às cenas fashion transportadas de realidades degradadas para espaços nobres, envolvendo nesta operação um séquito de embasbacados estilistas, arquitetos, maquiadores e conselheiros de toda a ordem. O cotidiano que pertencia a todos se sacraliza em meio a rituais de gosto duvidoso. Interessante que a profanação não se dá, mas novos aprisionamentos. Tudo é passível de uma foto, de uma visibilidade seja no twitter, seja no site etc., etc. Nada parece escapar da visibilidade que cria grande promiscuidade.

Luiz Camillo Osório (2005) comenta que as estratégias poéticas de certas obras tanto podem significar banalização, como novas possibilidades de se pensar e experimentar a arte e atribui grande importância às diferentes maneiras de se ver o mesmo objeto que não se reduz ao visível. As mudanças nos procedimentos poéticos que levaram a multiplicação de suportes e de formas expressivas - incluídas aí a performance, o happening, o vídeo, os objetos, as instalações etc. - obrigam-nos também a redefinir as noções de autoria de obra, de modos e de tempos de recepção. Como exemplo, citaria o trabalho de Matthew Barney mudando o espírito do carnaval. "No mundo de Matthew Barney, a verdade da arte não é a da natureza, e a natureza parece simples demais diante da arte. Com gravidade, sem humor, de um modo sacralizado, Barney cria seu universo de artifícios, onde tudo é investido por um calafrio de morte, e os desejos parecem congelados, para além de um estilo ou da moda". (COLI, 2003, p. E1, Ilustrada).

\section{Pós-produção e ampliação do campo artístico}

É comum ao visitante de uma exposição ficar mudo ou confuso diante das novas relações estabelecidas entre os objetos e na adjetivação dos novos processos que implicam na crise da autoria, na produção coletiva, alta dose de conceituação criativa com inclusão da figura do artista, rebaixamento das 
temáticas como bem mostram os grafites dos museus, intervenções pela cidade, notadamente em áreas degradadas e, finalizando, a quebra dos padrões de novidades e transcendência que marcaram a arte moderna e seus manifestos.

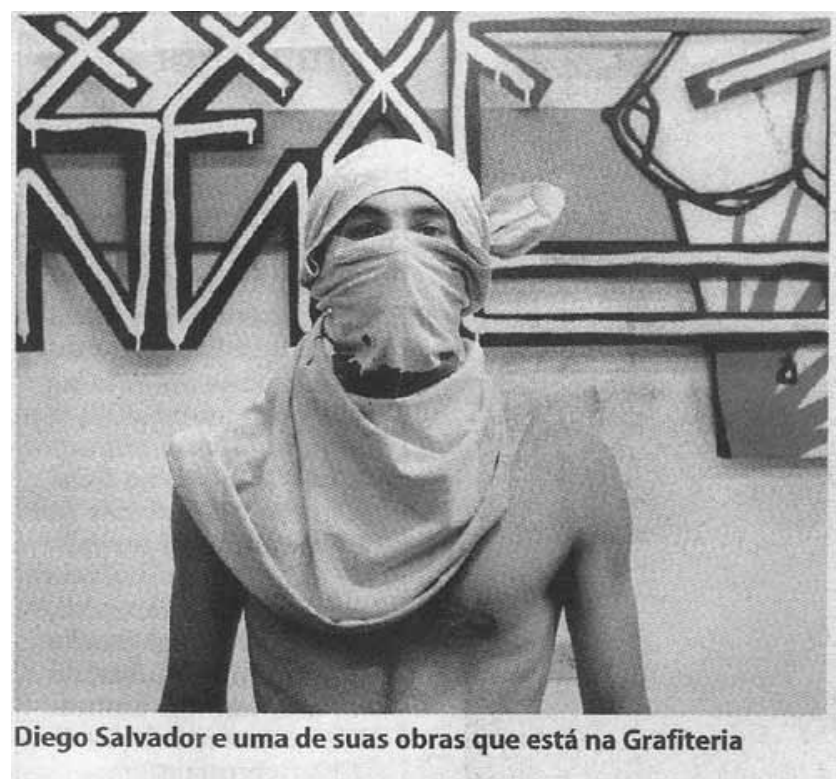

O termo pós-produção (BOURRIAUD, 2009) de certa forma orienta esse ensaio, designando uma característica da arte contemporânea em trabalhar materiais já dados. Como conjuntos de atividades ligadas ao mundo dos serviços e da reciclagem, a pós-produção faz parte do setor terciário em oposição ao setor industrial ou agrícola. Essa arte da pós-produção corresponde tanto a uma multiplicação da oferta cultural quanto - de forma mais indireta - à anexação ao mundo da arte de formas até então ignoradas ou desprezadas. Pode-se dizer que esses artistas que inserem seu trabalho no dos outros contribuem para abolir a distinção tradicional entre produção e consumo, criação e cópia, ready-made e obra original. Já não lidam com uma matériaprima. Para eles, não se trata de elaborar uma forma a partir de um material bruto, e sim de trabalhar com objetos atuais em circulação no mercado cultural, isto é, que já possuem uma forma dada por outrem. Assim, a noções de originalidade (estar na origem de...) e mesmo de criação (fazer a partir do nada) esfumamse nessa nova paisagem cultural.
Figura 4: Diego Salvador 
Figura 5: José Maurício

Gomes, o Zemog

Figura 6: Farnese de Andrade
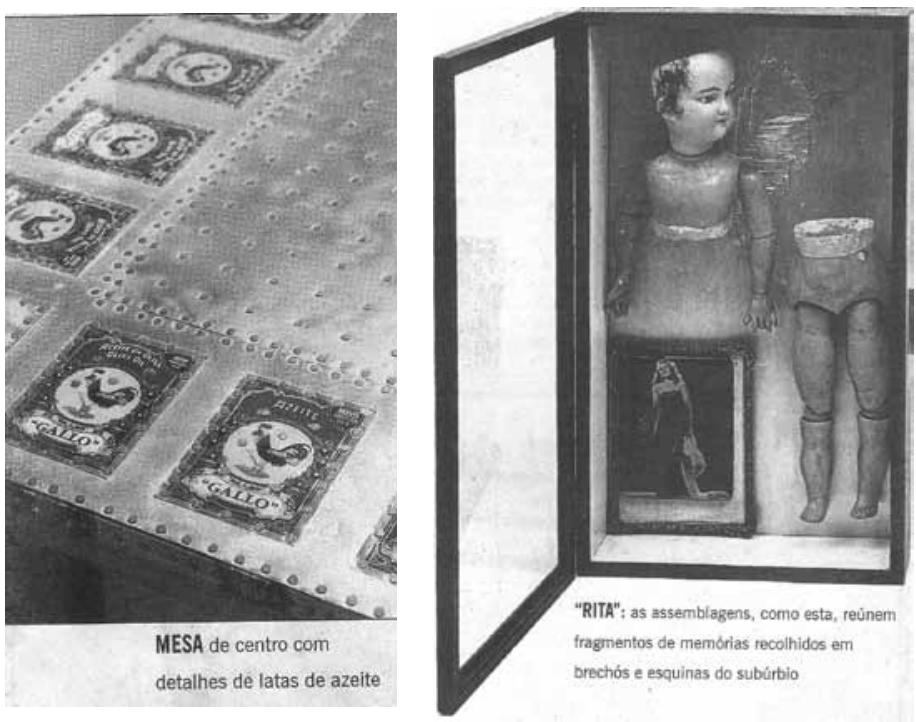

A Estética relacional, também de autoria de Bourriaud (2009), descreve a sensibilidade coletiva na qual se inserem as novas formas da prática artística e que tomam como ponto de partida o espaço mental mutante que a internet, instrumento central da era da informação em que ingressamos, abriu para o pensamento. Mas a Estética relacional tratava do aspecto convivial e interativo dessa revolução (as razões pelas quais os artistas se dedicam a produzir modelos de socialidade para serem inseridos na esfera inter -humana), enquanto a Pós-produção apreende as formas de saber geradas pelo surgimento da rede: em suma, como se orientar no caos cultural e como deduzir novos modos de produção a partir dele. De fato, é surpreendente que as ferramentas mais usadas para produzir esses modelos relacionais sejam obras ou estruturas formais preexistentes, como se o mundo dos produtos culturais e das obras de arte constituísse um estrato autônomo capaz de fornecer instrumentos de ligação entre os indivíduos; como se a instauração de novas formas de socialidade e uma verdadeira crítica às formas de vida contemporâneas passassem por uma atitude diferente em relação ao patrimônio artístico, pela produção de novas relações com a cultura em geral e com a obra de arte em particular. 


\section{Torre - Totem do artista plástico Cildo}

\section{Meirelles}

Em tempos de cultura global assistimos a formação de uma enorme miscigenação em diversos campos cujos princípios de seleção são muito difíceis de identificar. Isto não nos joga inevitavelmente num espaço de indiferenciação que caracteriza a subjetividade contemporânea no meio da discussão sobre a possibilidade de criar e referenciar o discurso artístico. O ecletismo contemporâneo não importa necessariamente num pecado capital se analisado fora da visada linear da arte historicista centrada no Ocidente. O conceito de pós-produção busca pensar a arte como a forma de uso do mundo, uma negociação infinita entre pontos de vista. A arte afinal consiste em produzir relações com o mundo materializando suas relações com o tempo/espaço.

A arte vem se inscrevendo no quadro deste controle generalizado pela imagem adquirindo traços de mercadoria sempre menos aurática, sempre mais espetacular. Recorre a modelos modernos sem a força do sujeito que quer transgredir, mergulha na abjeção, no cotidiano e em todo pastiche passível de espetacularidade. Passada a fase da representação, atravessado a simulação ela se locupleta olhando-se a si mesma, engolida pela metrópole em seu urbanismo voraz que faz aparecer não um corpo em ação, mas o que Baudry (2004) chama de "corporeidade". Segundo Baudry, a corporeidade é justamente um encontro do desajuste entre sujeito e si mesmo. Sua não adequação consigo, com a cidade, sua não essencialidade ou substancialidade. Neste sentido, os movimentos contemporâneos de dessubjetivação podem eventualmente representar pontos de fuga na homogeneização e indiferenciação iluminando o fundo obscuro onde aparece a criação. Um aspecto a ser analisado dentro deste contexto é o de pensar fora da coincidência que se supunha na época da representação como adequação com o real e também não se restringir ao virtual como tecnologia criativa. Mário Costa referiu a arte contemporânea como um lugar de construção do novo homem, entendendo aí o corpo e o encontro com a técnica.

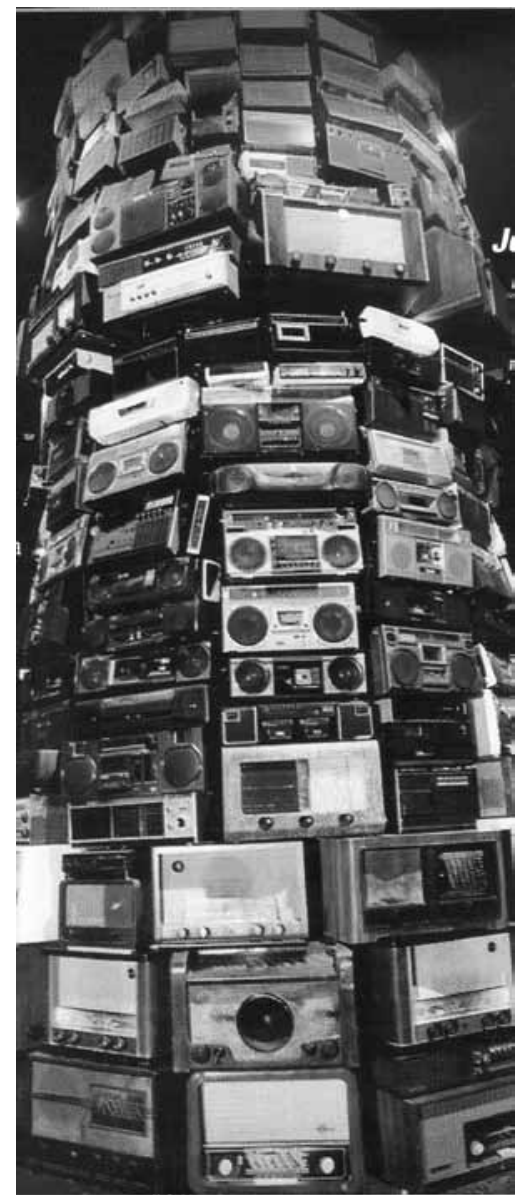

Figura 7 


\section{Os desafios à humanidade}

"Os artistas são antes de mais nada homens que
pretendem tornar-se inumanos".
Apollinaire.

O humanismo afirmava o homem como um valor seguro, com a faculdade inclusive de suspender e interditar a suspeição. Lyotard vai se perguntar se não é próprio do homem ser habitado pelo inumano. Aponta dois tipos de inumanidade e a necessidade de mantê-los dissociados: a do sistema em curso de consolidação, sob o nome de desenvolvimento (entre outros), e aquela infinitamente secreta de que a alma é refém (LYOTARD, 1990, p. 10).

Lyotard opta pela manutenção da indeterminação entre o humano e o inumano. Se o título de humano, segundo o autor, pode e deve caminhar entre a indeterminação nativa (infantil) e a razão instituída ou a instituir-se, também o pode e deve o inumano. E pergunta como resistir ao inumano do desenvolvimento. Que mais resta para opor resistência, que a dívida que toda a alma contraiu com a indeterminação miserável de sua origem da qual não cessa de nascer? Ou seja, com o outro inumano?

A tarefa da escrita do pensamento da literatura das artes é, para o autor, aventurar-se a prestar um testemunho, diverso do positivismo lógico, do racionalismo. Enquanto o princípio da razão se precipita para o fim, para a resposta, as traduções de pensamento não ocidentais oferecem uma atitude muito diferente. O que interessa não é a resposta, mas o questionamento, a manutenção da inquietação. A problemática derridiana do descentramento e da diferença, o princípio deleuziano de nomadização dependem, apesar de diferentes, desta aproximação do tempo como escuta.

No âmbito do pertencimento fusional do sujeito e do mundo em suas diversas escalas, descrito por Morin, o sujeito não é o do controle, mas o do trânsito, do trâmite, da mediação. O que se desconstrói, aqui, é tanto o sujeito forte cartesiano quanto o sujeito fraco descrito por Vattimo (1987). Na "passibilidade" na escuta descrita por Lyotard há uma noção de estoicismo que nos leva direto ao pensamento de Mário Perniola (1994) ou de Anne Cauquelin (2008) quando descre- 
ve o momento estóico na arte contemporânea na ótica do que chama indiferença enquanto expressão dos incorporais. Ora é convocado o tempo na sua monotonia; ora é o vazio sob todas as suas formas (buraco, branco) e incidentes inesperados que convocam o momento estóico do impreferível.

\section{Coisa entre coisas: a subjetivação como enigma}

"Fosse eu apenas não sei onde ou como, uma coisa existente sem viver".

Fernando Pessoa

Vivemos numa sociedade de imagem, mas devíamos nos referir a uma sociedade das coisas, ou seja, à da ruptura com o subjetivismo. Não se trata de um nihilismo que se substituiria à arrogância do sujeito da razão, mas uma atitude enigmática que permite uma ligação direta com a sociedade. $\mathrm{O}$ enigma não é uma dificuldade, um obstáculo, um limite à busca da verdade. Com Heráclito, a experiência do enigma adquire uma dimensão filosófica plena. Ultrapassa a oposição entre segredo e revelação e abre para uma linguagem que "não diz nem oculta", acena apenas. A importância de Heráclito reside no fato de ele ter afirmado o caráter unitariamente enigmático da realidade: não uma visão dualista do mundo, mas um combate de opostos coexistentes. No início da filosofia ocidental, encontramos uma profunda negação de identidade e uma rigorosa formulação da natureza do trânsito como "repousante transmutar e transmutante repousar" (PERNIOLA, Op. Cit., p. 35).

$\mathrm{O}$ enigma não consiste na mudança, na possibilidade do novo; a mudança é possível apenas sob a condição de a coisa permanecer a mesma e, vice-versa, a coisa permanece a mesma só na mudança. Mesmidade como trânsito e trânsito como mesmidade. O tempo do enigma é o presente. Ele nasce justamente do colapso tanto do passado quanto do futuro num presente ambíguo e problemático. Este tipo de experiência não nasce do retorno do recalcado nem do choque do futuro. Nem a hermenêutica, nem a utopia. Assistimos a uma inversão entre o homem e as coisas: os homens tornam-se parecidos com as coisas e o mundo inorgânico, graças à tecnologia eletrônica, parece substituir-se ao homem na percepção dos fenômenos.

$\mathrm{Na}$ linha deleuziana, diante do enigma contemporâneo, a atitude não é buscar a transparência, a verdade de um se- 
gredo, mas desenvolver as pregas, seguir os labirintos ("volvo"), percorrer as diversas camadas, entretecendo junto coisas diferentes, estabelecendo o continuum através de transições insensíveis ("flecto") numa transversalidade entre os planos ("clino"). O pensamento da prega não é nihilista, mas estóico. A razão filosófica funde-se aludindo a este momento de coincidência entre o antigo e o futurível, a este momento barroco, Perniola caracteriza a sociedade contemporânea como neo-apática e neo-pagã. Neo-apática, pelo culto da indiferença; neo-pagã, pela possessão. Ambas as experiências representam uma ruptura com o subjetivismo, um perder-se de si, um sentir-se via de passagem de algo exterior.

Na vertente neo-apática descreve, por exemplo, a passagem da cultura pop (ainda subjetivista) à cultura punk e póspunk ("no future, no feelings"). A união entre o vídeo e a cultura juvenil na vídeo-music marca a desvitalização da figura humana pela separação da voz e do corpo num efeito diferente do cinema mudo quando a falta de palavra não fazia senão exaltar a expressividade da figura humana. No vídeo-clip, as figuras humanas, geralmente privadas de voz, dão impressão da objectualidade, coisificam-se.

Também na passagem da moda à anti-moda e ao look, ele acentua a mesma dessubjetivação. O look é a autonomização das aparências: a imagem torna-se coisa. O look anula a nudez como a veste, instaura uma paisagem.

A dimensão neo-pagã por sua vez estaria articulada com a hibridização de culturas na atualidade e o desejo de ser tomado por outras tonalidades emocionais: possessão, delírio, transe.

\title{
Escrituras fractais da subjetividade: a função poética
}

\author{
"Terminei por achar sagradaa desordem \\ de meu espírito". \\ Rimbaud
}

Guattari (1992) pensa que considerar a subjetividade sob o ângulo da produção é sair dos sistemas tradicionais de determinação do tipo infra-estrutura material, superestrutura ideológica, uma vez que os diferentes registros semiológicos que engendram a subjetividade não obedecem a relação hierárquica.

Há a necessidade de forjar uma concepção mais transversalista e dinâmica da subjetividade, revendo a leitura, por 
exemplo, das máquinas tecnológicas de informação e comunicação que operam no núcleo da subjetividade humana. A evolução maquínica deverá ser julgada de acordo com suas articulações, com os agenciamentos coletivos de enunciação. Poderemos chegar a um estágio de re-singularização da mídia, saindo da opressão atual.

O autor examina os aspectos etológicos e ecológicos que seriam da ordem de um paradigma estético. As formações pré-verbais infantis não seriam fases no sentido freudiano, mas subjetividades nascentes que não cessaremos de encontrar no sonho, no delírio, na exaltação criadora, no sentimento amoroso.

Os diferentes registros de produção e recepção da arte hoje apontam, portanto, algumas tendências, mas, sobretudo, convida o público a participar desta inadequação da arte aos velhos parâmetros e criar usos inventados criativamente pelo corpo e pelo pensamento.

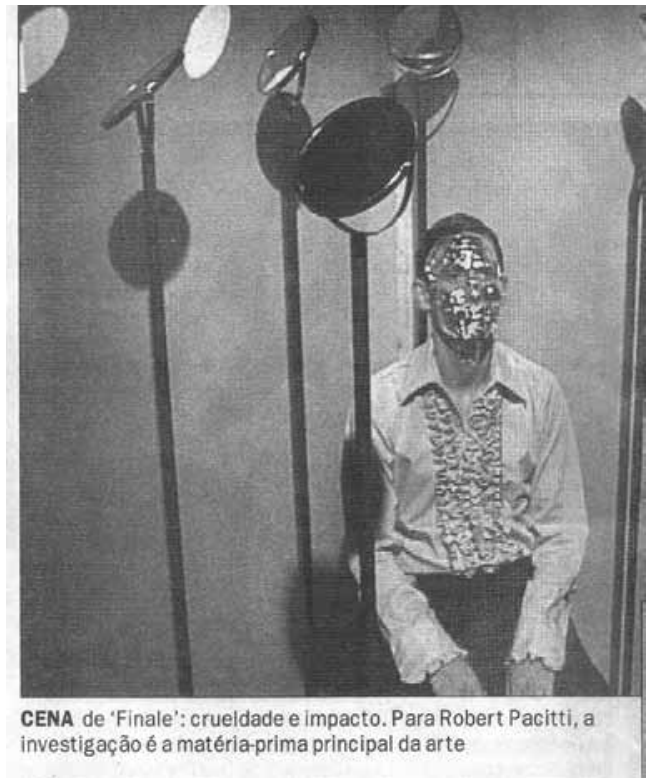

Figura 8: Robert Pacitti

\section{Referências}

AGAMBEN, Giorgio. O que é contemporâneo? e outros ensaios; tradução Vinícius Nicastro Honesko. Chapecó, Santa Catarina: Argos, 2009.

BAUDRILLARD, Jean. Telemorfose; prefácio e tradução Mu- 
niz Sodré. Rio de Janeiro: Mauad, 2004

BAUDRY, Patrick. Violences invisibles: corps, monde urbain, singularité. Paris: Passant, 2004.

BOURRIAUD, Nicolas. Pós-produção: como a arte reprograma o mundo contemporâneo; tradução Denise Bottman. São Paulo: Martins Fontes, 2009.

BOURRIAUD, Nicolas. Estética relacional. São Paulo: Martins Fontes, 2009.

CAUQUELIN, Anne. Frequentar os incorporais: contribuição a uma teoria da arte contemporânea; tradução Marcos Marcionilo. São Paulo: Martins Fontes, 2008.

COLI, Jorge. "A importância de Matthew Barney". In: Folha de S. Paulo, 14 de dezembro de 2003.

GRENIER, Catherine. Dépression et subversion: Les racines de l'avant-garde. Paris: Centre Pompidou, 2004.

GUATTARI, Félix. Caosmose: um novo paradigma estético; tradução Ana Lúcia de Oliveira e Lúcia Cláudia Leão. Rio de Janeiro: Ed. 34, 1992.

LYOTARD, Jean François. O inumano. Lisboa: Estampa, 1990. OSÓRIO, Luiz Camillo. Razões da crítica. Rio de Janeiro: Jorge Zahar, 2005.

PERNIOLA, Mário. Enigmas: o momento egípcio na sociedade e na arte. Lisboa: Bertrand, 1994.

VATTIMO, Gianni. La fin de la modernité: nihilisme et hermeneutyque dans la culture post moderne. Paris: Seuil, 1987.

\section{NOTAS}

1- AGAMBEN, Giorgio. O que é contemporâneo? e outros ensaios; tradução

Vinícius Nicastro Honesko. Chapecó, Santa Catarina: Argos, 2009.

2- GRENIER, Catherine. Dépression et subversion: Les racines de l'avantgarde. Paris: Centre Pompidou, 2004.

3- BAUDRILLARD, Jean. Telemorfose; prefácio e tradução Muniz Sodré. Rio de Janeiro: Mauad, 2004, p. 19-20.

4- OSÓRIO, Luiz Camillo. Razões da crítica. Rio de Janeiro: Jorge Zahar, 2005 .

5- COLI, Jorge. "A importância de Matthew Barney". In: Folha de S. Paulo, 14 de dezembro de 2003, p. E-1. Ilustrada.

6- BOURRIAUD, Nicolas. Pós-produção: como a arte reprograma o mundo contemporâneo; tradução Denise Bottman. São Paulo: Martins Fontes, 2009 .

7- BOURRIAUD, Nicolas. Estética relacional. São Paulo: Martins Fontes, 2009. 
8- BAUDRY, Patrick. Violences invisibles: corps, monde urbain, singularité. Paris: Passant, 2004.

9- LYOTARD, Jean François. O inumano. Lisboa: Estampa, 1990, p. 10.

10- VATTIMO, Gianni. La fin de la modernité: nihilisme et hermeneutyque dans la culture post moderne. Paris: Seuil, 1987.

11- PERNIOLA, Mário. Enigmas: o momento egípcio na sociedade e na arte. Lisboa: Bertrand, 1994 .

12- CAUQUELIN, Anne. Frequentar os incorporais: contribuição a uma teoria da arte contemporânea; tradução Marcos Marcionilo. São Paulo: Martins Fontes, 2008.

13- PERIOLA, Mário. Op. Cit., p. 35.

14- GUATTARI, Félix. Caosmose: um novo paradigma estético; tradução Ana Lúcia de Oliveira e Lúcia Cláudia Leão. Rio de Janeiro: Ed. 34, 1992.

Recebido em: 01/04/11

Aceito em: 26/o6/11

\section{NIZIA MARIA VILLAÇA}

nmvillaca@uol.com.br

Pós-doutorado em Antropologia, Paris V, Sorbonne; PROF. Titular da Escola de Comunicação/UFRj; pesquisadora CNPq e FAPERJ; livros, entre outros: Mixologias: comunicação e o consumo da cultura. São Paulo: Estação das Letras e Cores, 2010; A edição do corpo: tecnociência, artes e moda. São Paulo: Estação das Letras, 2007; O novo luxo. São Paulo: Anhembi Morumbi. (Org. c/Kathia Castilho), 2006; Em nome do corpo. Rio de Janeiro: Rocco. (Co-autor Fred Góes), 1998; Paradoxos do pós-moderno: sujeito \& ficção. Rio de Janeiro: UFRJ, 1996. 